\title{
Contribuições das ciências sociais em face dos entraves à educação para sociedades sustentáveis
}

\author{
Aloísio Ruscheinsky \\ Universidade do Vale do Rio dos Sinos, Brasil
}

Resumo

O objeto da investigação centra-se no debate sobre educação e sociedades sustentáveis e as interrogações a propósito deste significado, com a respectiva entonação ideológica. O campo do ambientalismo está desafiado em suas proposições, tanto pelas inovações e seus riscos tecnológicos quanto pela dialética de agregar aos direitos de cidadania também a contemporânea emergência de direitos ao e do meio ambiente. $O$ objetivo é apresentar, sob o enfoque das ciências sociais, algumas provocações sobre a denominação, os condicionamentos e os nexos entre educação e sociedades sustentáveis, de tal forma que tais aspectos atentam às tensões prementes e suscitem, no debate, tanto interrogações urgentes quanto a busca por práticas sociais e responsabilidades públicas. $O$ resultado almejado é apontar controvérsias envolvidas no nexo entre atores socioambientais e a constituição de sociedade sustentável. É a tentativa de contribuir com um amplo esforço empreendido para forjar multiplicadores ou agentes de educação ambiental, interrogando o cuidado efetivo ou envolvimento subjetivo, bem como políticas eficientes ante a crise ambiental.

Palavras-chave

Sociedades sustentáveis; Direitos; Atores socioambientais; Dialética.

\section{Introdução}

O problema de investigação do presente texto consiste em apresentar a contribuição das ciências sociais ante uma proposta de educação ambiental 
que subsidie a construção de sociedades sustentáveis. Essa perspectiva enseja um amplo desafio epistêmico e político para intelectuais, pesquisadores, educadores, associações civis e políticas ambientais. $O$ propósito é discorrer sobre a trajetória do debate e das práticas sociais no campo educacional, visando consolidar sociedades sustentáveis, cuja perspectiva incide no exame de dimensões, entre as quais: espaços, saberes e experiências; avaliação de projetos de educação ambiental; conseqüências para a educação da relação homem-natureza e do nexo entre culturanatureza; emergência de uma cultura alicerçada no consumo de bens e a multiplicação de resíduos; identificação das causas políticas e culturais da crise socioecológica; desenvolvimento de uma nova cultura pós-materialista na defesa do ambiente saudável numa sociedade de risco.

O esforço de estabelecer uma conexão sólida entre educação ambiental e construção de sociedades sustentáveis possui entraves, condicionantes e percalços históricos, mas, por certo, passará pelo reconhecimento da interdisciplinaridade e da transversalidade nesta abordagem ${ }^{1}$. Nesse sentido, há um trânsito de paradigma articulando as tensões entre os interesses do indivíduo, da sociedade e da preservação da natureza. Uma perspectiva de educação ambiental entrelaçada a sociedades sustentáveis incorpora, além das questões teóricas, técnicas e operacionais, as mediações pedagógicas e sociais e, igualmente, um conjunto diferenciado de desejos, de afetividade, de sonhos e de utopias. Um processo de educação em direção a sociedades sustentáveis poderá abraçar alguma vertente de interpretação da inexorável relação entre sociedade-natureza ou cultura-natureza: ecologia profunda, modernização ecológica, ecologia social, ecofeminismo, reflexividade e complexidade, meio ambiente socialmente construído, sociedade de risco, entre outras.

A teoria da ação ou da prática social oferece um questionamento da racionalidade e da razão instrumental de que se nutrem a produção e o consumo, de que estão imbuídas a ciência e a tecnologia contemporânea, bem como permeiam nosso cotidiano. Assim, ao longo do texto, a ótica predominante será a perspectiva dialética entre o instituído e a mudança, entre o factual e o cogitado. Entre as premissas postas da educação rumo a sociedades sustentáveis, aloca-se a permanência da dialética (como tensão e diálogo) entre as dimensões individuais e coletivas, entre identidade e estranhamento, entre a dimensão privada e a esfera pública, entre a 
articulação e o conflito, entre o material e o simbólico, entre os direitos humanos e ambientais e os condicionantes históricos, entre as gerações do presente e do futuro, entre atores sociais e instituições, entre preservar/conservar e revolucionar o sistema. Todavia, para o nexo entre sustentabilidade e educação não há no horizonte da análise um projeto na perspectiva redentora, uma visão de caminho imprescindível, mas uma proposição que implica outra perspectiva, com a reconstrução da realidade ou dos rumos possíveis para imprimir outro ritmo à história.

Os autores utilizados para demonstrar uma inserção no debate das ciências sociais dialogam entre si na perspectiva da crítica social, da crítica à modernidade, embora de perspectivas epistemológicas não idênticas. A razão da escolha se deve à ótica dialética para tratar do nexo 'ambiente e sociedade' e à crítica da sociedade contemporânea, com sua lógica científica ou razão instrumental que a ampara. Ao mesmo tempo, tal formulação não é exclusividade de uma tendência epistemológica ${ }^{2}$. Nesse rol, incluem-se autores reconhecidamente filiados: à teoria crítica, à crítica pela ótica da modernidade tardia e à abordagem da sociedade de risco. Todas estas perspectivas incorporam conquistas do movimento ecológico e se propõem pensar alternativas para a degradação ambiental, ou seja, aventam elementos para sociedades sustentáveis. Essa singularidade admitida faz jus ao rumo que se visualiza para o futuro: pluralidade, diversidade, incerteza, sem uma teoria exclusiva de interpretação das mudanças sociais, ou ator social único, detentor da direção da história.

A educação para sociedades sustentáveis, amparada em amplo conjunto de políticas públicas, bem como em largo envolvimento intersubjetivo, por sua vez assinala a internalização dos custos ambientais e a ponderação do impacto ambiental diferenciado das atividades. A forma como os saberes, o conhecimento, as pesquisas, a propósito de sociedades sustentáveis, incidem e se difundem pode ser verificada mediante as informações disponíveis na rede de computadores. Esta é mais do que uma mera curiosidade oferecida para reafirmar a interrogação sobre o significado atual de denominações como desenvolvimento sustentável, sustentabilidade e sociedades sustentáveis. Considero que há sensíveis diferenças na compreensão quando os atores utilizam uma das expressões alternativas de educação para, e ou em sustentabilidade ${ }^{3}$. A primeira expressão linguística 
tende a estar carregada de normatividade ou de diretividade dos autores do discurso para outro campo ou setores populacionais onde se aplicaria o seu conteúdo. A junção dos termos educação e sustentabilidade corre o risco da permanência da segmentação de significados ou de uma justaposição. $A$ expressão educação em referência à sustentabilidade possui, na literatura e na prática, menor grau de incidência, porém compreende a visão de mundo na qual todos estão contemplados, de alguma forma, pela ação educativa. Esta última, embora de uso raro na literatura e na Web, apresenta-se apropriada para contornar a adoção de uma vertente normativa no debate em questão.

\section{Os cidadãos ante o debate imperioso da sustentabilidade}

Dentro das controvérsias inerentes ao debate em curso, põe-se em destaque o grau de autonomia ou dos condicionantes da educação para sociedades sustentáveis? A interrogação fundamental consiste em detectar com quais atores sociais este processo vai poder contar ou com os quais as mediações sociais somarão forças. Afirmar que a educação ambiental, de uma forma generalizada, consiste numa tarefa de todos desconsidera a tensão da orientação das forças sociais em conflito de interesses e alimentadoras de utopias ${ }^{4}$, bem como o curso da diversidade das lutas sociais em torno de projetos para a sociedade no presente e no futuro.

A abordagem de proposições para sociedades sustentáveis interroga sobre o grau de autonomia possível em face das corporações, as quais se sustentam na exaustão e na degradação dos recursos naturais. Do mesmo modo, questiona-se o nexo ou a quase dependência para com 0 financiamento público ou privado. Especialmente, na medida em que o Estado, como espaço de negociação dos conflitos, também está comprometido com a lógica desenvolvimentista, com empreendimentos econômicos e corporações, cuja prioridade, sob a lógica da concorrência, está distante do apreço à proteção ambiental. Em outros termos, trata-se de responder uma questão persistente: em nossa compreensão, a educação, rumo a sociedades sustentáveis, se desenrolará na ambiguidade entre as práticas sociais alternativas e a égide das instituições vigentes.

A democracia e os direitos humanos possuem sua gênese num espaço 
sócio-histórico adverso: embate com o absolutismo e a preponderância do gênero masculino, branco, e a cultura ocidental. De forma similar, se muitas lutas apostaram no reconhecimento dos direitos: das mulheres, dos trabalhadores, dos indígenas, dos afro-descendentes entre outros, na virada do milênio, muito esforço teórico e prático fornece recursos estratégicos em prol do reconhecimento dos direitos da natureza, dos ecossistemas, entre outros. Entretanto, para os relativistas, o ambientalismo situa-se entre as causas perdidas, bem como se tornam problemáticas quaisquer alternativas dentro da perspectiva democrática.

No processo social contemporâneo, encontram-se intimamente associadas as ameaças ao desemprego, os temores fundados da seguridade social e os riscos ambientais (Castel, 2005). O diálogo entre temas como segurança social e ambiental coaduna-se bem com o recorrente debate entre justiça e democracia, entre atores domésticos e transnacionais. A discussão de direitos atinentes ao meio ambiente decorre de crises concomitantes, de acordo com Altvater (1999), como a crise da democracia contemporânea, da ecológica e do Estado de Bem-Estar, tendo como horizonte as ambiguidades da modernização, tecnologia e distribuição de resultados. Há conhecimento ampliado o suficiente sobre as consequências e implicações das múltiplas atividades humanas, o que se traduz em possibilidades de prática política para desacelerar a degradação dos recursos naturais, visando ao uso sustentável e a um acesso universal (Santos, 2000). Portanto, é paradoxal, num regime democrático, que tanto necessita dos bens naturais para debelar a fome, as desigualdades e as injustiças sociais colocarem entre as prioridades a preservação desses mesmos recursos.

O despertar de uma educação na via de sociedades sustentáveis pode inspirar movimentos sociais para outra dimensão dos seus afazeres na política e as respectivas mediações para as mudanças cogitadas. De igual modo, os atores socioambientais podem empreender outra educação que não seja refém da ciência e da tecnologia, com sua racionalidade, nem impulsione novos e vorazes consumidores; por outro lado, pode expressar certa indistinção entre um amiúde agente consumidor e o estatuto de cidadão (Canclini, 1996), especialmente na medida em que, na atualidade, o aumento da capacidade de consumo tende a ocorrer em descompasso com a cidadania.

A crítica ambientalista, na proposição de sociedades sustentáveis, 
contempla um amplo questionamento do consumismo ${ }^{5}$ e do desperdício da camada enriquecida da sociedade contemporânea, bem como das desigualdades persistentes e das circunstâncias de sua mitigação dentro de padrões de consumo sustentáveis. Todavia, é muito conveniente destacar a heterogeneidade da sociedade contemporânea a respeito da temática em foco, mesmo porque, no interior do capitalismo, uma característica fundamental é a apropriação desigual dos resultados materiais e imateriais. Convém distinguir países empobrecidos que priorizam inclusão social, qualidade de vida ou níveis mínimos de bem-estar, mas que também possuem pouca tradição de luta ecológica. Acima de tudo, sofrem mais as consequências perversas do consumo contumaz de outros países, com saque aos recursos naturais e com relações bilaterais desiguais. Nesse sentido, também do ponto de vista ambiental, manifesta-se a iniquidade, que desafia as proposições de educação para sociedades sustentáveis em ambos os pólos das desigualdades persistentes. Há que reformular o ditado "pensar global e agir local", pois a dialética informa que o local também é reflexão e ação, ou que a reflexão local pode ter implicações gerais.

A radicalidade e a profundeza se redobrarão na medida em que a educação para sociedades sustentáveis se apresentar como movimento social, apontando para formas de organização e de participação. Enquanto movimento social, pode impulsionar um novo encontro com o campo político e cultural, gerando um protagonismo em prol da causa ambiental. Todavia, esta é uma trajetória, de fluxos e refluxos, de encontros e desencontros (Ferraro, 2006), de muitas tensões e articulações de atores. Como tal, há também o debate quanto às interfaces com a democracia representativa, com a agenda de partidos políticos, com os organismos do terceiro setor. A expansão da esfera pública, a emergência das gerações de direitos, a difusão da democracia deliberativa, a profusão de informações demandadas pelas novas tecnologias delineiam requisitos fundamentais que atuam sobre a responsabilização cotidiana dos cidadãos.

No Brasil, emergiram conselhos paritários em diversos níveis, fóruns, comitês, parcerias, como mecanismos decisórios intermediários e poder instituído. Todavia, o Estado de direito, com seus níveis de controle e de gestão, possui trâmites ambíguos em face da democratização das decisões. Talvez a tarefa árdua para nossa capacidade de reflexão e de interpretação 
das oscilações históricas consista em demonstrar a dialética entre o institucional e os movimentos sociais e ambientais. Se nós compreendemos bem os mecanismos sociais - diante de novas desilusões em face dos processos das eleições e do exercício desta forma de democracia -, estaremos cientes da persistência da realidade das desigualdades e da degradação ambiental. Aí a interrogação de Giovannini (1997): o que a democracia tem feito com o meio ambiente, uma vez que, até o momento, o meio ambiente foi favorável ao desenvolvimento da democracia? Há que se destacar em que condições a cultura política democrática, como uma cultura alicerçada no bem-estar humano, será capaz de efetivar uma política de proteção e de precaução ante a degradação ambiental. A abordagem crítica interroga se o sistema democrático e se a cidadania pode proteger-se das consequências nefastas da degradação ambiental ou da exaustão de recursos naturais. A interrogação que cabe diz respeito tanto ao tipo de ambiente requerido para a efetividade da cidadania quanto à qualificação de cidadãos requeridos para uma sociedade sustentável. Todos os direitos promulgados dependem do alento por parte da biodiversidade.

\section{Expectativas sociais, educação ambiental e inovação}

A insistência nas qualidades da natureza e do meio ambiente enfatiza a responsabilidade dos sujeitos sociais e a sua cultura política. O direito a um ambiente sadio e ao futuro ainda a desabrochar requisita cuidar da natureza, o que, para uns, consiste em responsabilidade assimétrica e, para outros, significa firmar um novo contrato natural entre as partes em conflito. A legitimidade da democracia está ameaçada pela fragilidade das deliberações e ações visando à biodiversidade e à preservação do meio ambiente como um espaço vital. Veja-se que a questão do outro, como uma condição do diálogo e de realização, situa-se tanto no que diz respeito aos seres humanos quanto às condições do meio ambiente dentro das quais se realizam as atividades humanas.

Tornou-se lugar comum, entre ambientalistas, afirmar que a perspectiva ecológica, compreendida na sua radicalidade, implica na possibilidade de uma sociedade mais justa, igualitária, democrática e capaz de estabelecer outra relação dos seres humanos entre si e com o meioambiente. Hoje, a noção de sociedade sustentável, além da presença entre 
intelectuais, pensadores ou revistas especializadas, está implícita em muitos movimentos sociais, de viés ecologista ou não, na sua dinâmica e radicalidade. Todavia, se os sujeitos sociais da proposição de uma sociedade sustentável já estivessem amplamente dados, seria plenamente em vão o debate aqui proposto.

A proposição da educação pela via de sociedades sustentáveis apresenta-se precisamente como um novo movimento voltado à inovação, à esperança, à utopia. Esse movimento alicerça e defronta as causas do controle social e da degradação ambiental por meio de profundas e contínuas agressões aos ecossistemas ${ }^{6}$. A reinvenção da utopia na contemporaneidade pode ser denominada de educação para sociedades sustentáveis. Todavia, para tal intuito, tornam-se fundamentais o conhecimento das dimensões dos impactos provocados pelo consumo e a capacidade de suporte do ecossistema. Mais do que isso, estão em questão estratégias para contornar as dimensões irracionais associadas aos bens materiais e imateriais. Entra em discussão destacar a principal contradição, na contemporaneidade, que é capaz de operar, como alavanca, a mudança no campo ambiental, para gerar uma sociedade sustentável (Foladori, 1999). Alguns autores relegam a contradição capital-trabalho de outrora para destacar a tensão entre sociedade e meio ambiente, ou ainda o deslocamento das apreensões para o campo do consumo. De certo modo, essas tensões contemporâneas não se apresentam como excludentes entre si, uma vez que se corporificam na contradição radical entre determinada forma de produção dos bens, com o correspondente consumo, e as implicações ante a devastação dos recursos por meio do uso acima do limite da capacidade do ecossistema.

As principais teses de sociedades sustentáveis podem ser sintetizadas ou questionadas a partir das contribuições de Beck (1997; 2002): (a) os cientistas e políticos possuem um posicionamento-chave para a interpretação dos riscos visíveis e invisíveis; (b) o crescimento perceptível e notório dos riscos tecnológicos e ambientais relativiza os posicionamentos de classe social, pois os efeitos desses riscos ampliados tendem a atingir, quase indistintamente, toda a população, conferindo um aspecto democrático; (c) o potencial político da inovação está condicionado à capacidade de desenvolver novas políticas híbridas em face da complexidade; (d) a relação entre conhecimentos de peritos e leigos sintetiza uma tensão na sociedade de risco; 
(e) a análise de sociedades sustentáveis lida com a consolidação das mediações, bem como com a relevância ou os condicionamentos das instituições; (f) a sociologia, como crítica social, possui um papel relevante para detectar os riscos por vezes imperceptíveis ou incorporados à lógica das relações sociais.

Crescentemente, os riscos tendem a ser similares para todos os cidadãos, podendo circunscrever-se uma acentuada ênfase para alguns setores sociais, mas nem sempre os pobres são os mais atingidos pelos efeitos. Pela análise da generalidade dos riscos, supera-se a existência de um determinismo em que um único fator origina qualquer questão, seja a partir da infraestrutura, sejam os efeitos dos riscos tecnológicos ou a partir da sociedade de consumo.

Se, de um lado, a internalização na estrutura do Estado retira relevância e radicalidade das questões ambientais, de outro, a internalização de longe não se apresenta homogênea no aparelho de Estado em suas diferentes instâncias. Sem sombra de dúvida, ocorreu uma institucionalização da questão ambiental. Mas como ampliar uma sociedade sustentável sem permear os meandros da institucionalidade e de alterar a lógica da burocracia? Este debate é a interrogação sobre os atores sociais que afirmam o discurso e munem, com a prática social, uma lógica de sociedade sustentável.

Os condicionamentos para que a alternativa possível chegue à efetividade são as contingências das possibilidades e referem-se à articulação de ordem cultural, política, econômica e ética. O desvelar de sujeitos sociais múltiplos e difusos é estratégia de planejar, acumular e ampliar forças para lográ-lo. Para tal, patenteiam-se como relevantes a articulação a partir de cada setor social local, as políticas de cada país e o desafio constitutivo de um sujeito multissetorial e internacional. Nessa análise, as ciências sociais atentam também para alguns princípios éticos que podem inspirar sociedades sustentáveis.

O movimento ambientalista prestou-se como um ator relevante para a internalização das questões ambientais, especialmente porque seu apelo contagiou setores intelectuais e acadêmicos e porque propugnava a formulação de políticas públicas. Concomitantemente, essas pressões levaram a que parte do sistema produtivo incorporasse medidas 
compensatórias, paliativas ou corretivas. A presença do movimento multifacetado Conferência Rio 92 combina o espaço na mídia para a divulgação de problemas, a multiplicação de análises científicas sobre a interação sociedade e meio ambiente, o nível sem precedentes do interesse societal por questões ambientais e a inovação traduzida pelo documento Agenda 21. Ao mesmo tempo, o movimento ambientalista no Brasil assimila que as questões ambientais em geral requerem engendrar uma legislação adequada, resoluções subjetivas e coletivas ou políticas públicas (Tristão, 2005).

O movimento ambientalista, sob o ponto de vista da crítica e em longo prazo, não é um movimento histórico, uma vez que, na sua multiplicidade, não cogita um projeto arrojado de sociedade alternativa ou substantivamente distinta do presente. Ao longo dos anos, a consciência ambientalista levou as exigências ambientais a superar a perspectiva monotemática, tendendo a sair do setorialismo e sectarismo. Na sua diversidade, contempla temas que possuem uma centralidade entre os problemas da modernidade: aqueles que abrangem os riscos das questões ambientais (Tavolaro, 2001). Ao longo da explicitação da perspectiva ambiental, modificou-se a visão sobre o desenvolvimento da tecnologia e de seus efeitos ambientais, bem como existem diferentes agentes sociais que endossam a sustentabilidade.

As análises socioambientais da sociedade contemporânea se equivocam caso endossarem a renúncia à idéia de sujeitos sociais com projeto político, mesmo que escabroso diante da tradição das práticas desconstrutivistas ou temáticas pós-modernas. A discussão da modernidade vem dando lugar ao relativismo cultural, em que as alternativas ante a crise ambiental e o conhecimento fragmentado, por vezes, situam-se distantes das questões socioambientais. Por ironia, as causas ambientais insistem em aspirar projetos de emancipação política, bem como repensar os sistemas de pensamento ou projeto de sociedade que, supostamente, faliram para superar as causas da degradação das condições ambientais.

Nesse sentido, a educação, visando a sociedades sustentáveis, requer que se explicite, de acordo com a ótica adotada, sejam denominados de agentes sociais ou atores os que materializam a proposta em sua dinâmica conflitiva. Os atores socioambientais para sociedades sustentáveis (Ruscheinsky, 2006) possuem aspecto difuso e múltiplo, pois que está 
superada a concepção de um ator único com papel histórico. O movimento ambientalista não representa uma ideologia unívoca e, por isso, questiona-se a denominação de 'alternativo' em termos gerais, pois contempla muitas falas, discursos e práticas socioambientais. Além do mais, outros movimentos incorporaram algumas bandeiras ambientais em suas demandas. Os atores socioambientais mobilizam recursos em situações heterogêneas, cuja agenda ambiental se traduz em práticas sociais; ao mesmo tempo, escoram um processo de negociação entre agentes sociais.

Uma ambiguidade permanece no que diz respeito ao ponto de partida para a compreensão quando se trata da radicalidade: o discurso e a prática radical consistem numa oposição ao capitalismo ou os efeitos soam maiores com a internalização da perspectiva ambiental em todos os âmbitos da sociedade? Onde se encaminham e resolvem os problemas ambientais: no mundo da vida e suas relações cotidianas complexas ou na construção de modelos sociais destacando a utopia da mudança social?

Outro dilema refere-se à aproximação entre ambientalismo e partidos políticos. Para Giovannini (1997) e Alexandre (2000), quanto maior a aproximação entre atores sociais e organizações, ou quanto mais o ambientalismo assume o formato de partido, mais se afasta da temática e perde sua originalidade. O paradoxo da representação e da governabilidade ratifica-se por meio da experiência dos partidos verdes que se formaram com certa perspectiva radical, entretanto quase todos perderam a radicalidade nas articulações políticas para acessar o poder de Estado. As soluções que se requerem para uma perspectiva ecológica passam por um leque quase infindo de problemas complexos e sua resolução. Da trajetória do ambientalismo nas veredas da institucionalidade se destacam: Partido Verde, eventos internacionais ou intergovernamentais, legislação ambiental como nova racionalidade, gestão ambiental empresarial com as devidas certificações. Em algumas circunstâncias, a agenda ambiental se qualificou com governos de esquerda; em outras, as inovações ambientais se configuraram insignificativas. 


\section{Dialética contemporânea: insurgência de direitos ao e do meio ambiente}

A teoria crítica ajuda a refletir sobre as ambiguidades, os percalços e as contradições da emergência de novos direitos, em particular o movimento que conduz aos direitos referidos ao meio ambiente (Foladori, 1999; Tavolaro, 2001). Em outros termos, a argumentação alicerça a proposição de sociedades sustentáveis, porquanto esta perspectiva dá continuidade e radicaliza um humanismo ecológico.

O reconhecimento demarcado da complexidade dos conflitos ambientais, a abordagem interdisciplinar para superar o paradigma da fragmentação, a inclusão do conflito como parte integrante do processo social e o encantamento com as redes sociais e ambientais não conduzem inexoravelmente a uma abordagem sistêmica dos processos. Se, por um lado, a abordagem sistêmica na investigação nas ciências sociais conduz à compreensão do real em sua complexidade, por outro, ela fica alheia às condições de mudanças no sistema e das potencialidades da prática dos atores sociais.

A perspectiva histórico-crítica - inspirada na compreensão dialética da história, também denominada de teoria crítica (Freitag, 1990; Loureiro e outros, 2006) - afirma os direitos humanos como decorrentes dos conflitos inerentes à história, produtos e conquistas das lutas de atores sociais. Esses direitos emergem no decorrer da história, forjam-se em fluxos e refluxos, de acordo com a ideologia inerente às lutas sociais que os inspiraram, bem como alicerçados nos condicionantes históricos, ótica sob a qual também se inscreve a educação para sociedades sustentáveis.

A capacidade da crítica estabelece também uma prospectiva para as lutas sociais, a efetivação dos direitos, de cuja base não poderá prescindir da educação para sociedades sustentáveis. A crítica contida na abordagem requer um otimismo referente à ação social de atores multissetoriais. Cabe ao ambientalismo estabelecer a vinculação da crítica e do discurso emancipador com a práxis política de movimentos sociais concretos. Com tal mediação, a abordagem favorece as lutas de uma forma prática, uma teoria crítico-prática (Wolkmer, 2005). Convém anotar que a perspectiva crítica aqui aludida possui, entre as suas características fundamentais, a aposta de que outra sociedade é possível. Todavia, as mudanças concernentes à sustentabilidade 
nas questões ambientais possuem um ritmo aquém do desejado e das demandas dos atores socioambientais.

Parece equivocado o diagnóstico de influentes cientistas ou políticos, sugerindo que as disposições para a resolução dos complexos problemas ambientais estariam fortalecidas atualmente na medida em que informações de cuidados com o meio ambiente já fariam parte do imaginário social. Esse questionamento se deve ao fato da necessária distinção ou certa distância entre o acesso à informação e a respectiva prática socioambiental. A nomeação de direitos do meio ambiente atesta claramente a discussão sobre a mutabilidade, as tensões irresolvidas e os conflitos inerentes aos direitos advindos de lutas históricas entre ou na confluência de forças sociais. Nesse sentido, o acompanhamento do debate demonstra o quanto os direitos continuam sendo construídos nas tensões objetivas e subjetivas, na dialética histórico-social.

A promessa da modernidade de emancipação humana não tem sido cumprida na mesma medida em que se efetuou a promessa de dominação e subordinação completa da biodiversidade. As desigualdades persistentes e descontínuas se acentuam tanto entre as nações, entre os indivíduos, quanto no que diz respeito aos nexos entre sociedade e natureza (Goldblatt, 1996). Nesse sentido, as lutas sociais das últimas décadas, em parte, são caracterizadas por uma nova ética da alteridade $^{7}$ ou o reconhecimento de direitos do meio ambiente, impulsionadores de uma nova dimensão aos direitos humanos.

A discussão das relações dialéticas entre as gerações de direitos desemboca inexoravelmente - em seu sentido prospectivo - em considerações sobre a emergência de direitos ambientais. A tensão dialética entre as gerações de direitos se justifica, de um lado, na medida em que são heterogêneos e frequentemente conflitam entre si. De outro lado, existe uma clara complementaridade. Diga-se, de imediato: consiste na superação das condições pelas quais as atividades humanas operam a exaustão dos recursos naturais em detrimento das recomendações de preservação ambiental ou uso comedido. A reflexividade emergente, por vezes divergente da ótica da pós-modernidade, não se opõe à efetivação dos direitos humanos, porém agrega e objetiva outra convivência entre seres humanos e direitos de perpetuação de recursos naturais imprescindíveis. 
A insurgência do movimento ambientalista em prol de direitos concernentes ao meio ambiente sustentado, em um árduo e lento processo de construção, possui também a sua face controversa por meio da incorporação na dinâmica de circulação de mercadorias. Um novo conjunto de exigências dos consumidores $^{8}$ e usuários produz mudanças na oferta também no mercado de bens materiais e a construção do significado imaterial (Canclini, 1996). Por ironia, essa ideologia de respeito às leis da natureza está se alastrando de tal forma que a propaganda a associa a determinados produtos industriais que degradam recursos naturais, como se correspondessem aos princípios ambientalistas. O desperdício e o consumo suntuoso são transvestidos de protetores ambientais, sejam carros, cosméticos ou bancos, sem o efetivo reconhecimento de novos direitos ora cogitados. Pelo exposto, a expansão dos direitos humanos pode ser dialeticamente contraposta aos direitos da natureza ora emergentes. Em outros termos, está posto o debate sobre educação ambiental para sociedades sustentáveis.

Entretanto, existem notáveis obstáculos na cultura política para assegurar direitos ao meio ambiente, pois só se conferem direitos a quem é passível de corresponder, portanto de quem se pode exigir deveres. Esse é o caso dos bens ambientais;

Isto explica por que razão, na concepção ocidental dos direitos humanos, a natureza não possui direitos: porque não the podem ser impostos deveres. Pelo mesmo motivo, é impossível garantir direitos às gerações futuras: não possuem direitos porque não possuem deveres (Santos, 2001: 79).

Nesse sentido, há uma associação ou sincronia entre cultura política e educação em sociedades sustentáveis.

O desafio é construir a alternativa de se atribuírem esses novos direitos a entes sem voz ou representação política e sem a exigência de deveres como contrapartida em razão de os recursos serem imprescindíveis 9 . Nesse sentido, em diversos momentos e movimentos, cogita-se a proposição de declarações como "carta da terra", "carta dos direitos humanos da natureza", carta da água. É a extensão do conceito de cidadania dentro de uma reciprocidade de direitos ou complementaridade, ofuscada pela velocidade dos descartáveis e da vida artificial. A educação para a sustentabilidade requer uma ética da alteridade fundada no princípio da responsabilidade. Neste último caso, pode-se dizer que "a natureza, não nos 
sendo idêntica, é-nos recíproca na medida em que, por exemplo, a sua destruição acarreta a nossa própria destruição. Assim, a nossa subjetividade não se completa sem ela" (Santos, 2000: 81). Neste embalo, recomenda-se uma racionalidade ambiental, o uso comedido de recursos naturais dentro dos limites da capacidade de suporte do ecossistema, pois, em nenhuma circunstância, a riqueza da biodiversidade não pode ser substituída por valor pautado em dólares.

A proposição de direitos de ótica ambiental situa-se no conflito de interpretação de sociedades sustentáveis, do que se considera qualidade de vida, ou ainda acentua o conflito entre pólos opostos, como os empenhos de preservação de recursos e os outros interesses que demandam e consagram a produção e o consumo. Isso significa que se encontra embutida, na educação em sociedades sustentáveis, outra concepção de qualidade de vida que ultrapassa a trajetória do Estado de bem-estar. A dialética contemporânea de insurgência de direitos ao e do meio ambiente fundamenta tanto o uso sustentável de recursos naturais, a abordagem multissetorial, a opção por estratégias culturais e estruturais, quanto a articulação de processos de equidade social encaixados à capacidade de suporte do ecossistema.

\section{Agentes multiplicadores e práticas sociais em educação ambiental}

A fim de aprofundar o exercício de reflexão sobre agentes sociais da educação em sustentabilidade, voltamos o olhar para os efeitos de projetos diversificados de ótica ambiental no Brasil, que, na sua diversidade, constituem uma frágil identidade para a educação ambiental (Layrargues, 2004). Em face das consequências dos empreendimentos para suscitar experiências de sucesso, poderíamos comparar o número de indivíduos capacitados como multiplicadores da educação ambiental e as práticas socioambientais locais. Decorrem daí os resultados deste esforço em face das relações entre os indivíduos, entre sociedade e natureza, bem como a emergência de uma política de saneamento básico, de ações no cotidiano, de mudanças de comportamento sobre consumo ${ }^{10}$, entre outros aspectos. A especificação da abordagem se deve ao fato de tentar se esquivar de uma abordagem idealizada e, em curso diverso, explicitar aspectos de experiências locais, bem como agentes que materializam a proposição de 
educação no encalço de sociedades sustentáveis.

A apropriação e a reafirmação da capacidade analítica e crítica das ciências sociais apresenta-se uma tarefa do presente e urgente, pois, com isso, apartam-se do risco de se tornarem descartáveis como outra mercadoria da sociedade de consumo. Aspectos que tendem a influenciar na crítica social e nas iniciativas referentes às questões metodológicas e a perspectivas teóricas são: (a) a concepção de Educação Ambiental como treinamento, adestramento ou capacitação para uma finalidade explícita, suscitando uma racionalidade instrumental; (b) a preocupação que conjugue, de forma consistente, os efeitos visíveis com as causas das questões ambientais; (c) a articulação e as interfaces entre atores sociais ligados à questão ambiental; (d) a consolidação de crítica à sociedade de consumo, à colonização do cotidiano e da subjetividade pelas mensagens do mercado e da mercantilização de todas as coisas; (e) a reinvenção de uma mística ou de uma ética ambiental diferenciada, à semelhança do espírito de cidadania, do amor ou da paixão pelo futebol; (f) a apropriação da perspectiva da compaixão no sentido de respeito e de não colonizar espaço do outro, isto é, compartilhar a paixão do outro ou a sinergia da vida.

Para a nossa reflexão, cabe interrogar o quanto a linguagem usual, decorrente de uma visão de sociedade, carece de modificações visando a um processo de educação para sociedades sustentáveis. Além do mais, as ciências sociais podem auxiliar no destaque das condições para construir uma linguagem inteiramente apropriada para um projeto socioambiental ou o diagnóstico de uma educação ambiental para sociedades sustentáveis. Os atores socioambientais abalizam os encontros e desencontros na interpretação (Ferraro, 2006), bem como no delinear das práticas sociais adequadas e um novo contrato socioambiental. Por exemplo, se utilizar-se a abordagem do ecodesenvolvimento, está-se diante do dilema para dirimir o grau de vestígios das atuais condições de desenvolvimento que, a qualquer custo, exploram recursos naturais, além do que os conceitos e os conhecimentos podem ser apropriados e institucionalizados por outros campos.

Um programa de educação ambiental para sociedades sustentáveis pode contemplar a ação de atores sociais em temas como: (1) o fortalecimento da auto-estima, da cidadania e da autonomia, num contexto em 
que tende a aumentar a dependência dos indivíduos de múltiplas informações e carência de discernimento; (2) as interfaces dinâmicas entre ciência, tecnologia, meio ambiente, informação e inclusão social para romper com a crueldade das desigualdades; (3) o acompanhamento de agentes multiplicadores, sem que represente uma forma de controle ou coerção social; (4) os desdobramentos da capacidade de desenhar o que poderia contemplar um novo contrato entre pares que, além de social, também incluiria o ambiental; (5) a instituição da pré-ciclagem - preferência a produtos ecologicamente corretos - e o manuseio exemplar da pedagogia do reduzir, reutilizar e reciclar.

As questões ambientais requerem atividades multissetoriais, ou seja, reativas, impulsionadas por fiscalizações de órgãos públicos, pela legislação ou pelas pressões de mercado e por uma perspectiva proativa de atores para sociedades sustentáveis. Aos pesquisadores cabe realizar um diagnóstico que sirva de orientação para o desenvolvimento catalisador de ações, bem como induza à perspicácia de sensibilizar, projetando nova cultura de responsabilidade socioambiental (Sato \& Carvalho, 2005). Isso constitui, ao mesmo tempo, um prognóstico de sociedades sustentáveis e a cogitação de uma nova sociabilidade, ou uma moral capaz de outro olhar que reconheça direitos aos bens naturais (Tavolaro, 2001). Neste conflito, situa-se o movimento em defesa do acesso à água potável como um direito humano universal.

As questões ambientais e a educação para sociedades sustentáveis conjugam-se como alternativas para vislumbrar a superação da fome e da pobreza, com a decorrente redução das desigualdades persistentes nos diferentes contextos sociais brasileiros. Isto no sentido contrário do que proclamam os estrategistas sistêmicos e o pensamento hegemônico de que somente o crescimento econômico e a tecnologia alargada podem suscitar justiça social e ambiental. De forma similar como a fome expressa a natureza persistente das desigualdades sociais, a degradação ambiental expressa as circunstâncias da desigualdade entre sociedade e meio ambiente.

As questões pertinentes à gestão ambiental parecem insuficientes ante a complexidade em curso, ao menos da compreensão usual, quando se trata de políticas ambientais. Redclift (2000) expõe uma crítica contundente às premissas da gestão ambiental como resolução dos conflitos em face das 
práticas de consumo. A capacidade de um ecossistema sustentar a biodiversidade em sua diversidade, sem sofrer degradação ou incorrer em depreciação de repor-se, é chamada de capacidade de suporte. Aqui e acolá, há práticas sociambientais para enfrentar o colapso do ecossistema, onde a natureza em ruínas aparece na forma de colapso (Kurz, 2004). A exaustão pode advir da ocupação e do uso desordenados da concentração urbana, dos mecanismos de produção, dos padrões insustentáveis de consumo, entre outros aspectos.

Os desdobramentos de um olhar sobre projetos de educação ambiental, especialmente em região com larga degradação dos recursos naturais, desembocam na preocupação com as questões ambientais e a traduzem para a ordem do dia na esfera pública: empresas, ONGs, entidades de classe, academia, administração pública, noticiário dos veículos de informação. $O$ descaso com especiais cuidados atinentes ao meio ambiente, em particular na virada da década, o aquecimento global e a água ${ }^{11}$ vêm de longa data, causando enormes modificações e preocupações aos ambientalistas. Neste sentido, constitui-se um âmbito de educação e articulação para sociedades sustentáveis.

A relação entre a sociedade e a natureza é demarcada, por um lado, pela visão implacável do desenvolvimentismo, associada com a expansão do consumo e, por outro, pela façanha de reduzir os indivíduos a espectadores dos desdobramentos na sociedade. Esses indivíduos, inseridos na sociedade de consumo e ansiosos por qualidade de vida, estão submetidos à impotência ou à indiferença frente à proteção ambiental. Diante de perspectivas pessimistas, Sachs (2004) entende, na complexidade crescente, a referida urgência do desenvolvimento como includente, sustentável e sustentada. Quando se trata da cultura de consumo, sob a ótica da confiança ou da incerteza, tem por base um conjunto de informações diante das quais os programas e projetos brasileiros de educação ambiental estão sendo desafiados.

A carência de um conhecimento crítico em face da sociedade de consumo, na compreensão de Loureiro e outros (2006), em especial como uma sociedade de risco ambiental, permite centrar as atividades dos projetos educativos em questões quase efêmeras: recolhimento de latas e papéis, campanha de limpeza do pátio e rios, confecção de objetos com materiais 
reutilizados, descrição de problemas ambientais, coleta e reciclagem, plantio de mudas, visitação a áreas de preservação. Da mesma forma, parece equivocada a tentativa de atribuir às novas gerações o quinhão árduo de reconhecer e cunhar, no futuro, sociedades sustentáveis.

Sob o enfoque da teoria crítica, o debate ambiental também pode conjeturar falsos problemas quando atribui a degradação ambiental de maneira predominante ao consumo, sendo que a resolução consiste em reduzir a consumação para proteger o meio ambiente, em reutilizar ou reciclar os rejeitos após algum uso. Essa deliberação responsabiliza em demasia os indivíduos e somente dá conta, de forma parcial, do movimento da reflexividade. Por outro lado, desonera as relações sociais ou redime o militarismo e a lógica de acumulação propriamente dita, bem como minimiza as ações do Estado de bem-estar e as políticas de saneamento. Portanto, apregoar a autolimitação individual ou centrar na responsabilidade individual revela uma perspectiva restrita para dimensionar a complexidade da sustentabilidade socioambiental.

Os anseios e encantos com os bens de consumo, com freqüência, fazem sucumbir as preocupações com a contingência dos recursos naturais e minimizam o cuidado ou o tornam fugaz no cotidiano. Os valores da educação ambiental e proposições atinentes às regras do mercado soam contraditórios, quando não excludentes (Foladori, 1999; Loureiro et ali., 2006). A racionalidade do consumo sequestra aspectos fundamentais embutidos no debate das questões ambientais e, ao mesmo tempo, desemboca na difusão de crenças que, por sua vez, desencadeiam um processo de idolatria e paixão que exige sacrificar o meio ambiente. A Educação Ambiental surge, em circunstâncias concretas, como uma tentativa de tornar viável o rompimento com o paradigma da degradação ambiental, afirmado pela premissa de que 0 meio ambiente e os recursos naturais são inesgotáveis.

O espaço dos projetos socioambientais é compreendido como um campo que assimilou a complexidade das relações sociais, materiais e simbólicas, bem como de disputa de interesses, minando a construção dos sentidos da questão ambiental na sociedade contemporânea. A sustentabilidade para a questão ambiental é uma construção social (Redclif \& Woodgate, 1997), cujos percalços as ciências sociais temem em desvendar. Tudo indica que, se há fragilidade dos projetos de educação ambiental, esta 
consiste no intercâmbio efêmero entre atores sociais num cenário em que contribuem para a conformação do espaço urbano construído, bem como a sua disposição em aliar causas e efeitos dos problemas ambientais. De outro lado, convém agregar o fenômeno do associativismo e sua capacidade de expressar demandas frente ao poder público, sendo que, no mesmo ritmo, encontra-se a realidade de muitos conselhos e fóruns instituídos como mecanismos intermediários de deliberação e ordenamento do espaço urbano.

Está em curso, todavia, a busca de legitimação das preocupações e das práticas sociais em face dos processos de degradação, a construção de um campo de conhecimento interdisciplinar, a justificativa para a existência de formas associativas (ONGs) e de órgãos públicos ou instâncias decisórias cuja ação prima pelo viés ambiental. As iniciativas de setores sociais específicos, multissetoriais e multifacetados para reverter o processo de degradação por meio da Educação Ambiental ainda ressentem-se do volume de facetas para estancar o descaso histórico com o meio ambiente, bem como para desenhar um processo de sociedades sustentáveis.

Concluindo, temos a impressão de que, a cada dia ou a cada conquista diante da perspectiva de constituição de passos decisivos na direção de sociedades sustentáveis, colocam-se outros tantos obstáculos e desafios. A sociedade da mercantilização universal mantém-se fecunda em suscitar percalços, entre os quais se situa, ainda hoje, o desenvolvimento a qualquer custo, bem como a expansão e afirmação do consumo como sinônimo de qualidade de vida. Além do mais, a educação tem que dizer sobre os sucessivos avanços tecnológicos em campos tão multifacetados, atingindo a ousadia da mescla do humano com o não humano.

No caso brasileiro, há uma tradição de abordagem militante nas ciências sociais que aprendeu que a institucionalização da questão ambiental ou a intransigência militante pode levar à perda da visão crítica legada pela contemporaneidade.

$\mathrm{Na}$ tradição da "imaginação sociológica", os setores intelectuais próximos às causas ambientais não se eximem da autocrítica para tornar próspera a capacidade analítica: defrontam-se para averiguar o quanto estão imersos no imaginário de consumo; interrogam todas as formas de poder e confrontam as formas de dominação; dilatam o olhar sobre a produção de consequências nefastas ao meio ambiente. Adotar uma perspectiva crítica ou 
interpretação dialética significa compreender os direitos numa simbiose entre reflexão e ação, entre teoria e prática social, entre planejar e executar ou tomar posição no momento presente de acordo os conflitos, apesar do caráter contraditório inerente. A construção dos direitos forja-se como sínteses e superações, convenção acordada e conflitos perpetuados. Dessa maneira, situam-se no bojo de um processo de mudanças, no conflito das interpretações e na dinâmica do movimento como um devir histórico.

O futuro, de alguma forma, já está antecipado no tempo do possível, de alternativas em gestação na realidade social, cujas imagens e imaginário fundam as ponderações sobre sociedades sustentáveis. Todavia, o cientista social jamais olvida que o possível é também recheado de incerteza ou de vitalidade utópica. O futuro pode ser compreendido tanto como a superação quanto a dilatação do presente. Assim sendo, sociedades sustentáveis situam-se no horizonte das possibilidades ou num movimento a expandir-se nas experiências sociais factuais e possíveis, porquanto o presente é um campo de pistas de um futuro possível. O futuro escorre pelas brechas do presente ou é nos resíduos da vida social que a inovação pode ser pensada e o possível pode ser ilustrado. A abordagem na perspectiva de sociedades sustentáveis alimenta-se da sociologia das emergências, tendo, no campo das experiências históricas, como substrato a sociologia das ausências.

Assim, concluo este texto na suposição de ter apresentado algumas provocações para suscitar o debate urgente e imperioso a respeito das travessias e travessuras da educação para sociedades sustentáveis.

\section{Notas}

1 No Brasil está sendo inserido no sistema do ensino médio, tanto a educação ambiental como tema transversal, quanto o ensino da sociologia e filosofia como temática obrigatória. Todavia, a sociologia, como a ciência da sociedade ou como um sistema de conhecimento, adquire esta inclusão exatamente num momento em que está sendo questionada a sua legitimidade de apontar soluções eficientes e plausíveis para os graves problemas socioambientais

2 Em termos dos referenciais da formação das teorias sociais, uns estão próximos a Marx e outros a Weber. Assim mantém distancia da sociologia dos sistemas ou da complexidade a partir de modelos organizacionais.

3 Os índices de ocorrências dessas expressões na rede de busca da web precisam ser relativizadas sob diversos aspectos. Dentre eles, está o fato de que estas 
incidências de número de sites variam de acordo com o horário, a oscilação e da capacidade da rede, manutenção dos hospedeiros. A navegação pode comprovar dificuldades de localizar referências nas quais estejam associadas ao mesmo tempo as questões da educação e da investigação para sociedades sustentáveis. O nexo destas expressões com o presente texto situa-se no fato de que o uso de uma ou outra denota uma especificidade no aludido debate sobre sustentabilidade.

4 Por esta razão cientistas, ambientalistas, acadêmicos alertam: se nós não mudarmos de prumo, pode ser que chegaremos onde estamos indo. Se quisermos chegar a outro lugar, talvez o primeiro passo nessa direção seja descrever o tipo de destino que queremos alcançar: sociedades sustentáveis.

5 Existem indivíduos, grupos e organizações, teorias acadêmicas que se propõem a divulgar uma perspectiva de consumo ético e, no limite, o de anticonsumerismo, com mobilização visando a educação do consumidor em face das conseqüências. Existem diferenças entre consumo orgânico, ético, verde, crítico e anticonsumerismo. Um cidadão brasileiro precisa, em média, do cultivo no espaço geográfico de dois campos de futebol para a sua sobrevivência, um norte americano requer dez campos e um português cerca de quatro campos de futebol.

6 A capacidade de suporte do ecossistema está sendo ultrapassada ou a biosfera não suporta os efeitos produzidos. O decrescimento é fazer decrescer os fluxos de matéria e de energia, mas também reconhecer que os automóveis verdes ou 0 biocombustível estão longe de ser a solução ambiental. Ainda mais do ponto de vista ético, hoje alimentar a população se coloca à frente de saciar carros e luxuosas necessidades. A demanda por transporte coletivo, de qualidade e de acesso a todos, significa combate parcial ao capital e à solução do problema da poluição atmosférica, pois significa menor circulação de automóveis e o ar nas metrópoles será mais respirável. O uso de energias limpas constitui-se tanto um avanço como um paliativo possível. O decrescimento implica também no declínio da arrogância da cultura ocidental e do antropocentrismo.

7 Esta perspectiva está posta na contramão da história recente, em divergência com a supremacia da dimensão econômica sobre o campo da deliberação política, em aversão às múltiplas faces da exploração e dominação humana e da biodiversidade.

8 Um possível papel social do consumidor implicaria que sua decisão poderia transformar-se em veto ou orientar a política de corporações, legitimando socialmente mecanismos de preservação ambiental. Todavia esta utopia está muito distante do horizonte, pois este consumidor está longe de exercer tal poder, porquanto exercer este poder de consumir um produto ambientalmente correto pode significar ou renunciar ao consumo ou pagar mais.

9 Dentro do Direito, as circunstâncias produziram a tutela dos bens naturais, em cujo procedimento o ordenamento protege recursos naturais e destaca os direitos difusos. Na elaboração da Carta Magna brasileira, aparece a formulação genérica do direito a um meio ambiente saudável. Porém, nestas duas décadas, tanto as práticas ambientais se modificaram quanto a compreensão dos direitos relativos ao ambiente.

$10 \mathrm{Na}$ realidade, o consumidor hoje possui muitas informações, mas poucas para entender efetivamente os impactos dos hábitos de consumo. Neste sentido as 
informações podem ser um obstáculo ao agir ecologicamente correto e multiplicar as dificuldades de contribuir com sociedades sustentáveis. Assim sendo, a educação ambiental pode contribuir com o discernimento e a seletividade para um consumidor menos passivo. Tal posicionamento significa cobrar e acostumar-se a absorver informações socioambientais do processo produtivo, do pré-consumo e pós-consumo. Para além da questão individual importa em demandar políticas públicas que incentivem desdobramentos sustentáveis em todas as dimensões. Confira entrevista de Lisa Gunn - coordenadora do Instituto Brasileiro de Defesa do Consumidor (Idec) - à IHU On-Line, http://www.unisinos.br/ihuonline. Igualmente confira-se entrevista com a pesquisadora Maria I. M. de Almeida "Um jovem cada vez mais autônomo e menos independente". Disponível em http://www.unisinos.br/ihuonline, acessado dia 19/09/2008.

11 É fundamental abordar, na ótica utópica de sociedades sustentáveis, a água potável, considerando-a um recurso natural renovável e direito humano fundamental, especialmente devido à sua prolongada e crescente degradação, sem o devido sistema de saneamento básico. Os rios já foram o centro de atenções em lazer e prazer, com profusas espécies, serviram de via de navegação ou porta de entrada das cidades. A partir da gênese das incertezas, vem sendo destruída a confiança e a credibilidade dos sujeitos sociais em face do sistema de abastecimento que oferece água de qualidade para saciar a sede da população nas cidades e proliferam as formas de mercantilização da água para consumo humano.

\section{Referências}

ALEXANDRE, Agripa F. (2000). A Perda da Radicalidade do Movimento Ambientalista Brasileiro: uma Contribuição à Crítica do Movimento. Blumenau: Edifurb/UFSC.

ALTVATER, Elmar (1999). Os desafios da globalização e da crise ecológica para o discurso da democracia e dos direitos humanos. In A. Heller (org), A Crise dos Paradigmas em Ciências Sociais e os Desafios para o Século XXI. Rio de Janeiro: Contraponto, pp. 109-153.

BECK, Ulrich (2002). La Sociedad del Riesgo Global. Madrid: Siglo Veintiuno.

BECK, Ulrich (1998). Risk Society. Towards a New Modernity. London/New Delhi: Sage Publications.

CANCLINI, Nestor G. (1996). Consumidores e Cidadãos: Conflitos Multiculturais da Globalização. Rio de Janeiro: Ed UFRJ.

CASTEL, Robert (2005). A Insegurança Social: o que é ser Protegido?. Petrópolis: Vozes.

FERRARO, Luiz (org.) (2006). Encontros e Desencontros da Educação Ambiental. Brasília: MMA/DEA.

FOLADORI, Guilhermo (1999). Sustentabilidad ambiental y contradicciones sociales. Ambiente \& Sociedade, Nepam, ano II, ㄲo 5.

FREITAG, Barbara (1990). A Teoria Crítica: Ontem e Hoje. 3aㅡ ed. São Paulo: Brasiliense. 
GIOVANNINI, Fábio (1997). A democracia é boa para o meio ambiente? Ambiente \& Sociedade, ano I, n. 1.

GOLDBLATT, Davi (1996). Teoria Social e Ambiente. Lisboa: Instituto Piaget.

HERCULANO, Selene; PORTO, Marcelo \& FREITAS, Carlos (Org.) (2000). Qualidade de Vida e Riscos Ambientais. Niterói: Eduf.

KURZ, Robert (2004). Com Todo Vapor ao Colapso. Juiz de Fora: UFJF/ Pazulin.

LAYRARGUES, Phillipe P. (coord.) (2004). Identidades da Educação Ambiental Brasileira. Brasília: MMA/DEA.

LEFF, Enrique (2001). Epistemologia Ambiental. São Paulo: Cortez Ed.

LEIS, Héctor (1999). A Modernidade Insustentável: as Críticas do Ambientalismo à Sociedade Contemporânea. Petrópolis-Florianópolis: Vozes/ UFSC.

LOUREIRO, Carlos F.; LAYRARGUES, Philippe P.; CASTRO, Ronaldo S. (org) (2006). Pensamento Complexo, Dialética e Educação Ambiental. Cortez Editora.

REDCLIF, Michael \& WOODGATE, Graham (2000). Reavaliando o consumo: uma crítica a premissas da gestão ambiental. In S. Herculano; M. Porto \& C. Freitas (Orgs.), Qualidade de Vida e Riscos Ambientais. Niterói: Eduf.

REDCLIF, Michael \& WOODGATE, Graham (1997). Sustainability and Social Construction. In M. Redclift \& G. Woodgate (Eds.), The International Handbook of Environmental Sociology. Cheltenham, UK: Northampton, MA.

RUSCHEINSKY, Aloísio (2004). Os novos movimentos sociais na luta pela água como direito humano universal. In I. Neutzling (Org.), Água: Bem Público Universal. São Leopoldo: Ed. Unisinos.

RUSCHEINSKY, Aloísio (org) (2004). Sustentabilidade: uma Paixão em Movimento. Porto Alegre: Sulina.

RUSCHEINSKY, Aloísio (2006). Atores socioambientais. In L. Ferraro (org), Encontros e Desencontros da Educação Ambiental. Brasília: MMA/DEA.

SACHS, Ignacy (2004). Desenvolvimento Includente, Sustentável e Sustentado. Rio de Janeiro: Garamond.

SANTOS, Boaventura S. (1999) Porque é tão difícil construir uma teoria crítica. Revista Crítica de Ciências Sociais. Lisboa, ํㅜ 54, pp. 197-215.

SANTOS, Boaventura S. (2000). A Crítica da Razão Indolente. Contra o Desperdício da Experiência. São Paulo: Cortez.

SANTOS, Boaventura S. (2001). As tensões da modernidade. Cidadania e Justiça. Rio de Janeiro, n.10, pp. 70-89.

SATO, Michele \& CARVALHO, Isabel (Orgs.) (2005). Educação Ambiental: Pesquisa e Desafios. Porto Alegre: Artmed.

TAVOLARO, Sérgio B. F. (2001). Movimento Ambientalista e Modernidade: Sociabilidade, Risco e Moral. São Paulo: Annablume/Fapesp.

TRISTÃO, Martha (2005). Tecendo os fios da educação ambiental: o subjetivo e o coletivo, o pensado e o vivido. Educação e Pesquisa. São Paulo: USP, v. 31, n. 2, pp. 251-264.

WOLKMER, António C. (2004). Novos pressupostos para a temática dos direitos humanos. In D. S. Rubio (Org.), Direitos Humanos e Globalização: Fundamentos e Possibilidades desde a Teoria Crítica. Rio de Janeiro: Lúmen Júris, pp. 103-116. 
CONTRIBUTIONS OF SOCIAL SCIENCES BEFORE BARRIERS IN EDUCATION FOR SUSTAINABLE SOCIETIES

\begin{abstract}
The object of this research focuses on the debate on education and sustainable societies and questions regarding its meaning and ideological views. The field of environmentalism is challenged by both, technological innovaions and their risks, and the contemporary dialectic that agregates the social rights, also emerging rights of and to the environment. The goal is to present, from the standpoint of social sciences, some provocation to the designation, constraints and links between education and sustainable societies, so that these aspects undermine difficulties and tensions raising in a debate urgent questions and the pursuit of social practices and public responsibilities. The desired result is to indicate controversies involving the nexus between environmental actors and constitution of sustainable society. Is an attempt to contribute to an effort undertaken to forge multipliers or environmental education agents questioning their effective care or subjective involvement and efficient policies and the environmental crisis.
\end{abstract}

Keywords

Sustainable societies; Rights; Socioenvironmental actors; Dialectic

\title{
CONTRIBUICIONES DE LAS CIENCIAS SOCIALES FRENTE LOS OBSTACULOS DE LA EDUCACIÓN EN LAS SOCIEDADES SUSTENTABLES
}

\author{
Resumen \\ El objeto de investigación se centra en el debate sobre educación y \\ sociedades sustentables y las interrogantes a propósito de este significado, \\ con la respectiva entonación ideológica. El campo del ambientalismo está \\ desafiado en sus proposiciones, tanto por las innovaciones y sus riesgos
}


tecnológicos como por la dialéctica de agregar a los derechos de ciudadanía también la contemporánea emergencia de derechos al/y del medio ambiente. El objetivo es presentar, bajo el enfoque de las ciencias sociales, algunas provocaciones sobre la denominación, los condicionamientos y los nexos entre educación y sociedades sustentables, de tal manera que tales aspectos atentan las tensiones preeminentes y suscitan, en el debate, tanto interrogantes urgentes como la búsqueda por prácticas sociales y responsabilidades públicas. El resultado deseado es apuntar controversias envueltas en el nexo entre actores socio-ambientales y la constitución de sociedad sustentable. Es la tentativa por contribuir con un amplio esfuerzo emprendido para forjar multiplicadores o agentes de educación ambiental, interrogando el cuidado efectivo o envolvimiento subjetivo, así como políticas eficientes ante la crisis ambiental.

Palabras clave

Sociedades sustentables; Direchos; Actores socioambientales; Dialectica

Recebido em Novembro/2008

Aceite para publicação em Fevereiro/2010

Toda a correspondência relativa a este artigo deve ser enviada para: Aloísio Ruscheinsky, Av. Unisinos, 950, 93022-900 São Leopoldo, RS, Brasil. 